\title{
Synthesis, Characterization and Corrosion Inhibition of decyl-2-[(5-methylisoxazol-2-yl)methyl]benzimidazole: Experimental and DFT Approaches
}

\author{
Jihad Sebhaoui ${ }^{a}$, Yasmina El Aoufir ${ }^{b, c}$, Youness El Bakri ${ }^{a}$, El Hassane \\ Anouar $^{d,}{ }^{*}$, Abdelkader Ben Ali ${ }^{b}$, Abdellah Guenbou ${ }^{b}$ and El Mokhtar Essassi ${ }^{a}$ \\ ${ }^{a}$ Laboratory of Organic Heterocyclicic Chemistry, Centre for Research of Medicine Sciences, \\ Pole of Pharmacochemistry Competences, URAC 21, Faculty of Sciences, \\ Mohammed V University Rabat, Avenue Ibn Battouta, P.O. Box 1014, Rabat, Morocco \\ ${ }^{b}$ Laboratory of Nanotechnology, Materials \& Environment, \\ Faculty of Sciences, University Mohammed V, Rabat, Morocco \\ ${ }^{c}$ Laboratory of separation processes, Faculty of Science, \\ University Ibn Tofail P.O. Box 242, Kenitra, Morocco \\ ${ }^{d}$ Department of Chemistry, College of Science and Humanities, Prince Sattam bin Abdulaziz \\ University, P.O. Box 83, Al Kharj 11942, Saudi Arabia
}

Received January 26, 2018; accepted September 14, 2018

\begin{abstract}
The corrosion inhibition efficiency of a new benzimidazole derivative, namely, 1-decyl2-[(5-methylisoxazol-2-yl)methyl]benzimidazole (DIB) for carbon steel in $1 \mathrm{M}$ hydrochloric acid $(\mathrm{HCl})$ was studied by EIS and PDP electrochemical methods. The results indicate that DIB reduces carbon steel corrosion rate in the corrosive medium, and its inhibition efficiency increased with the concentrations. The polarization data indicate that DIB is of a mixed type. EIS study reveals that DIB is adsorbed onto the corroding metal surface, creating a barrier between the acid and carbon steel. The DIB molecules adsorption fitted into Langmuir adsorption isotherm. Furthermore, DIB electronic properties that correlate to its corrosion inhibitory such as Eномо, ELumo, energy gap $(\Delta \mathrm{E})$, dipole moment $(\mu)$, electronegativity $(\chi)$, global hardness $(\eta)$ and the fraction of electrons transferred from DIB molecule to the metallic atom $(\Delta \mathrm{N})$, were calculated in PCM solvent at the B3LYP/6-311+G $(d, p)$ level of theory. The theoretical results are in good agreement with the observed corrosion inhibition efficiency of the tilted compound.
\end{abstract}

Keywords: benzimidazole; corrosion inhibition; electrochemical impedance spectroscopy; carbon steel; potentiodynamic polarization; DFT.

\footnotetext{
* Corresponding author. E-mail address: anouarelhassane@yahoo.fr
} 


\section{Introduction}

Corrosion is an undesirable phenomenon; it can originate severe damage to metals and alloy structures, causing economic significances in terms of products deterioration and replacement. Among metals, steel is most widely used in the industry; it suffers from a certain type of corrosion within some environments. Acidic solutions are widely used in industry. The most important areas of applications are acid pickling, industrial acid cleaning, acid descaling and oilwell cleaning [1]. Corrosion inhibitors are needed to reduce the corrosion rates of metallic materials in these acidic media. Most acidic corrosion inhibitors are nitrogen, sulfur, or oxygen-containing organic compounds. Although nitrogencontaining compounds function more effectively in hydrochloric acid, the stability of the inhibitor film formed over the metal surface depends on some physicochemical properties of the molecule, related to its functional groups, aromaticity, the possible steric effects, electronic density of donors, type of corrosive medium and nature of the interaction between the $p$-orbital of inhibitors with the $d$-orbital of iron [2-6]. Benzimidazole is a heterocyclic aromatic organic compound. This bicyclic compound consists of the fusion of benzene and imidazole. The most prominent benzimidazole compound in nature is N-ribosyldimethylbenzimidazole, which serves as an axial ligand for cobalt in vitamin $\mathrm{B}_{12}$ [7]. Benzimidazole is commercially available, but the usual synthesis involves condensation of o-phenylenediamine with formic acid [8]. Benzimidazole and its derivatives play a vital role in biological fields such as antimicrobial [9], antiviral [10], antidiabetic [11], antispasmodic[12], and anticancer activities [13].

In continuation of our work on the synthesizing new corrosion inhibitors [14-20], 1-decyl-2-[(5-methylisoxazol-2-yl)methyl]benzimidazole (DIB) was prepared, and its inhibiting properties on carbon steel corrosion in a hydrochloric solution were investigated using electrochemical and DFT approaches. In addition, the temperature effect on the corrosion inhibition properties of the tilted compound is emphasized.

\section{Materials and methods}

\section{Organic synthesis}

Synthesis of 1-decyl-2-[(5-methylisoxazol-2-yl)methyl]benzimidazole (DIB)

A mixture of 1-decyl-4-(2-oxopropylidene)-1,2,4,5-tetrahydro-2H-1,5benzodiazepine-2-one $\underline{\mathbf{1}}(10 \mathrm{mmol})$ and hydroxyl-amine hydrochloride (10 $\mathrm{mmol}$ ) in ethanol was refluxed for a period of $2 \mathrm{~h}$. After neutralization with $\mathrm{NaHCO}_{3}$, the formed residue was recrystallized from hexane, to afford DIB as a black solid with a good yield (97\%) and a melting point of $100-101{ }^{\circ} \mathrm{C}$ (Scheme 1).

The compound was characterized by NMR spectroscopy. ${ }^{1} \mathrm{H}-\mathrm{NMR}$ (DMSO- $\mathrm{d}_{6}$ ): $0.82\left(\mathrm{~s}, 3 \mathrm{H}, \mathrm{CH}_{3}\right), 1.57\left(\mathrm{q}, 2 \mathrm{H}, \mathrm{CH}_{2}\right), 4.28\left(\mathrm{t}, 2 \mathrm{H} ; \mathrm{CH}_{2}-\mathrm{N}\right), 6.14(\mathrm{~s}, 1 \mathrm{H}, \mathrm{CH}), 7.17-7.55$ (4H,CHaromatique) (d ppm): ${ }^{13} \mathrm{C}-\mathrm{NMR}$ (DMSO-d6) (d ppm): $12.19\left(\mathrm{CH}_{3}\right)$, 14.40 $\left(\mathrm{CH}_{3}\right), \quad 22.54-39.90\left(\mathrm{CH}_{2}\right.$-aliph $), 43.62(\mathrm{C}-\mathrm{N}), \quad 102.75(\mathrm{C}=\mathrm{C}), \quad 110.68-$ $142.82\left(\mathrm{C}_{\text {aromatique }}\right), 160,35(\mathrm{C}=\mathrm{N})$ and $169.90(\mathrm{C}=\mathrm{C})$. 


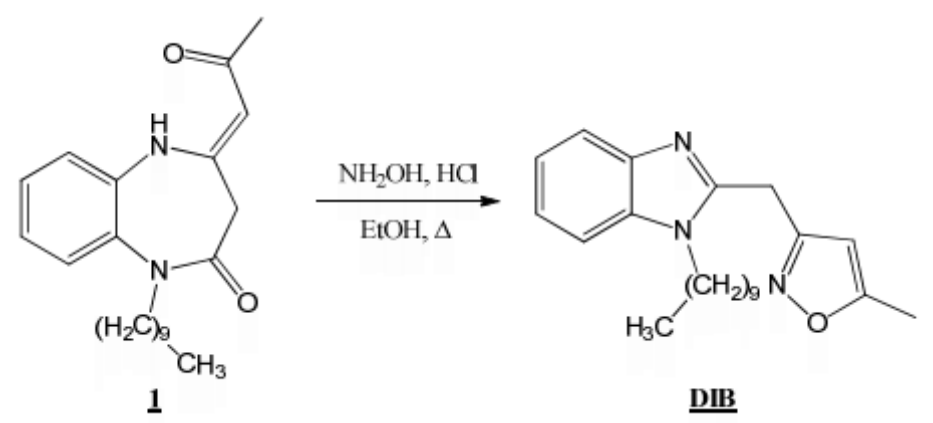

Scheme 1. Formation of DIB compound.

The proposed mechanism of the transformation of 1-decyl-4-(2-oxopropylidene)1,2,4,5-tetrahydro-2H-1,5-benzodiazepine-2-one $\quad \underline{\mathbf{1}}$ into 1-decyl-2-[(5methylisoxazol-2-yl)methyl]benzimidazole (DIB) using hydroxylamine hydrochloride in ethanol is illustrated in Scheme 2.

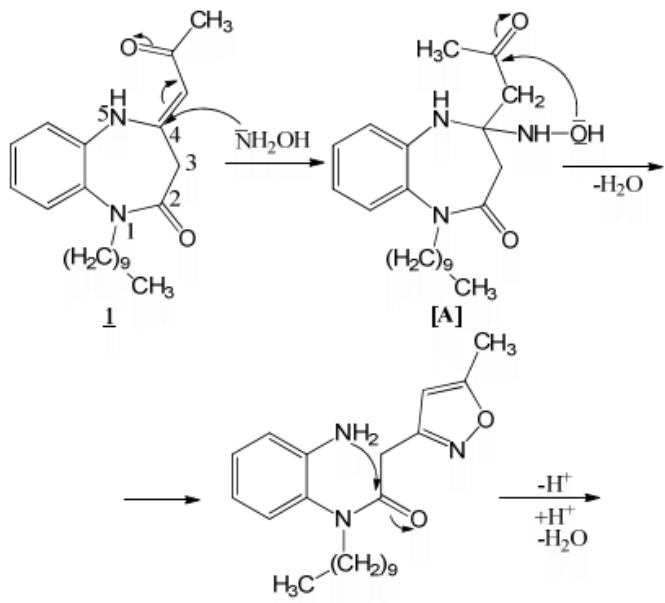

[C]

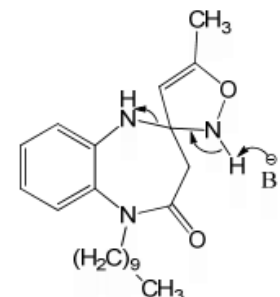

$\mathrm{CH}_{3}$

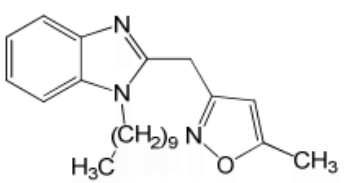

DIB

Scheme 2. Proposed mechanism for the formation of DIB.

The initial step of this ring transformation corresponds to the attack of the amino group of hydroxylamine on the electrophilic carbon in position 4 of the seven membered ring. The formed [A] intermediate undergoes an intramolecular cyclization to generate the [B] spiro compound. The latter compound, after an opening of the diazepine ring leads to [C] compound which, via an intramolecular cyclization, involving the amino and the carbonyl groups, gives, after losing a water molecule, the title 1-decyl-2-[(5-methylisoxazol-2yl)methyl]benzimidazole (DIB) compound.

\section{Electrochemical measurements}

Corrosion inhibition tests by electrochemical measurements in a $1 \mathrm{M} \mathrm{HCl}$ solution were performed using coupons prepared from carbon steel (VWR, Radnor, PA, U.S.A) having the composition: $0.370 \%$ of C, $0.230 \%$ of Si, $0.680 \%$ of $\mathrm{Mn}, 0.016 \%$ of $\mathrm{S}, 0.077 \%$ of $\mathrm{Cr}, 0.011 \%$ of $\mathrm{Ti}, 0.059 \%$ of $\mathrm{Ni}, 0.009 \%$ of $\mathrm{Co}$, $0.160 \%$ of $\mathrm{Cu}$ and the remainder iron $(\mathrm{Fe})$. For the electrochemical studies, specimens with an exposed area of $1 \mathrm{~cm}^{2}$ were used. The carbon steel specimens 
were polished with increasing grades of emery papers $(100,220,360,400,600$ and 1200 grit size), then degreased with acetone and washed with deionized water. Finally, the specimens were dried at room temperature. The aggressive solution was prepared by dilution of analytical grade $\mathrm{HCl}(37 \%)$ with distilled deionized water. The used acidic medium and acetone were obtained from VWR Chemicals (Leuven, Belgium). The concentrations of the studied inhibitors ranged from $10^{-3}$ to $10^{-6} \mathrm{M}$, and the volume of the test solution used for the electrochemical studies was $50 \mathrm{~mL}$. The test solutions were recently prepared before each experiment by directly adding DIB inhibitor to the corrosive solution.

A set of three-electrode cells containing carbon steel coupons of $1 \mathrm{~cm}^{2}$ surface was incorporated in the specimen holder as the working electrode (WE), a large area platinum mesh was used as counter electrode (CE) and a saturated calomel electrode as reference electrode (RE). The electrochemical methods were carried out by the means of a Volta lab (Radiometer PGZ 100) potentiostat, and controlled by corrosion analysis software (Voltamaster 4). The corrosion behaviour of the CS specimens was studied in a $1 \mathrm{M} \mathrm{HCl}$ solution, using EIS and potential polarization curves in the solutions without and with inhibitor. The CS was immersed in the test solution for $30 \mathrm{~min}$, to set up the $E_{\text {ocp }}$ balanced state. The EIS measurements were immediately performed under measured $E_{o c p}$, startup frequency ranged from $100 \mathrm{kHz}$ to $10 \mathrm{mHz}$, and an amplitude of $10 \mathrm{mV}$ (peak to peak). In the entire experiment, the Nyquist diagrams were fitted using the EcLab program. To get the corrosion parameters, the cathodic and anodic polarization tests were also performed starting from $E_{o c p}$, using a scan rate of 1 $\mathrm{mVs}^{-1}$, after reaching a steady $\mathrm{E}_{\text {ocp }}$ state. Experiments were performed in triplicate.

\section{DFT calculations details}

The starting geometry of 1-decyl-2-[(5-methylisoxazol-2-yl)methyl] benzimidazole (DIB) was optimized using the B3LYP hybrid functional, combined with a triple- $\zeta$ Pople-type basis set $6-311+\mathrm{G}(\mathrm{d}, \mathrm{p})$ as implemented in Gaussian software [21]. The minima of the optimized ground states were confirmed by the absence of imaginary frequencies, i.e, all imaginary frequencies are positive. A set of electronic properties, including HOMO and LUMO orbital energies, ionization potential (IP), electronic affinity (EA), energy gap between the HOMO and LUMO, electronegativity $(\chi)$, chemical hardness/softness $(\eta / S)$, electrophilicity $(\omega)$ and dipole moment $(\mu)$, were calculated for the tilted compound, in an attempt to rationalize their effect on the inhibition efficiency of the tilted compound. The selected descriptors were calculated using Koopman's theorem (IP $=-\mathrm{E}_{\mathrm{HOMO}}$ and $\left.\mathrm{EA}=-\mathrm{E}_{\mathrm{LUMO}}\right) \cdot \chi, \eta$ and $\omega$ were calculated using the following equations:

$$
\begin{aligned}
& \chi=\frac{I P+E A}{2}=-\mu \text { where } \mu \text { is the chemical potential } \\
& \eta=\frac{1}{2}\left(\frac{\partial \mu}{\partial N}\right)_{\mathrm{v}}=\frac{1}{2}\left(\frac{\partial^{2} E}{\partial \mathrm{N}^{2}}\right)_{\mathrm{v}}=\frac{(I P-E A)}{2}
\end{aligned}
$$




$$
\begin{aligned}
& S=\frac{1}{\eta} \\
& \omega=\frac{\mu^{2}}{2 \eta} \\
& \mu^{\prime}=\sqrt{\mu_{\mathrm{x}}^{\prime 2}+\mu_{\mathrm{y}}^{{ }^{2}}+\mu^{\prime}{ }_{\mathrm{z}}^{2}} \\
& \alpha=\frac{1}{3}\left(\alpha_{\mathrm{xx}}+\alpha_{\mathrm{yy}}+\alpha_{\mathrm{yy}}\right)
\end{aligned}
$$

In equations 2 and $3, N$ is the number of electrons, $v$ the external potential, and $\mathrm{E}$ the electronic energy. The fraction of the transferred electrons $(\Delta N)$ was calculated through the Pearson theory [22]:

$$
\Delta N=\frac{\chi_{\mathrm{Fe}}-\chi_{\mathrm{inh}}}{2\left(\eta_{\mathrm{Fe}}+\eta_{\mathrm{inh}}\right)}
$$

where $\chi$ is the electronegativity, $\eta$ is the hardness, $\mathrm{Fe}$ is iron atom and inh is the abbreviation for the inhibitor.

The active sites for the synthesized DIB that bound to the carbon steel surface were determined by calculating the Mulliken atomic charges. The solvent-solute interactions were implicitly taken into account by using the polarizable continuum model (PCM). In this model, the inhibitor is embedded into a cavity surrounded by a solvent described by its dielectric constant, $\varepsilon$, (e.g., for water $\varepsilon=$ 78.3553) [23]. The HOMO and LUMO frontier molecular orbitals were visualized using Molden software.

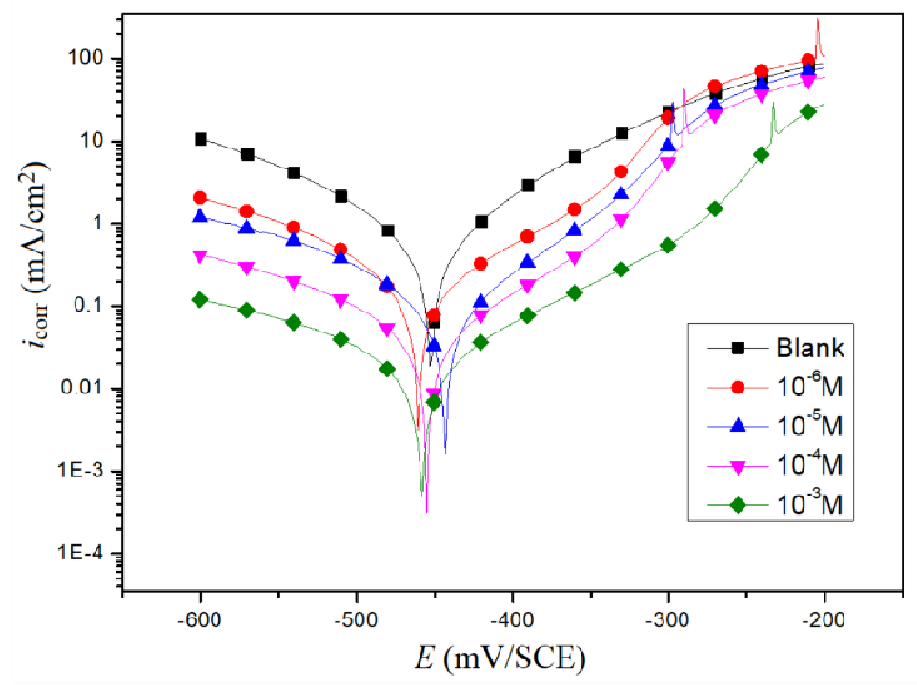

Figure 1. Potentiodynamic polarization curves for carbon steel at $303 \mathrm{~K}$ in a $1 \mathrm{M} \mathrm{HCl}$ solution in the absence and presence of DIB at various concentrations. 


\section{Results and discussion}

\section{Potentiodynamic polarization measurements}

Both anodic and cathodic polarization curves of carbon steel in $1 \mathrm{M} \mathrm{HCl}$ for different concentrations of the prepared inhibitor are shown in Fig. 1.

The addition of the inhibitor to a $1 \mathrm{M} \mathrm{HCl}$ solution was accompanied by an increase of the current density values near the corrosion potential, indicating that the inhibitor molecules retarded the corrosion process.

In addition, the parallel cathodic Tafel curves show that the hydrogen evolution was activation controlled, and that the reduction mechanism was not affected by DIB presence. Various electrochemical parameters were calculated from the corresponding polarization curves (Table 1).

Table 1. Kinetic parameters calculated from PDP measurements after $30 \mathrm{~min}$ of immersion in a $1 \mathrm{M} \mathrm{HCl}$ solution, without and with inhibitor at different concentrations, at $303 \mathrm{~K}$.

\begin{tabular}{ccccccc}
\hline Inhibitor & $\begin{array}{c}\text { Concentration } \\
(\mathbf{M})\end{array}$ & $\begin{array}{c}\mathbf{E}_{\mathbf{c o r r}} \\
(\mathbf{m V} / \mathbf{S C E})\end{array}$ & $\begin{array}{c}\mathbf{I}_{\mathbf{c o r r}} \\
\left(\boldsymbol{\mu} \mathbf{A} \mathbf{~ c m}^{-\mathbf{2}}\right)\end{array}$ & $\begin{array}{c}\boldsymbol{\beta}_{\mathbf{a}} \\
\left(\mathbf{m V} \mathbf{d e c}^{-\mathbf{1}}\right)\end{array}$ & $\begin{array}{c}-\boldsymbol{\beta}_{\mathbf{c}} \\
\left(\mathbf{m V} \mathbf{d e c}^{-\mathbf{1}}\right)\end{array}$ & $\begin{array}{c}\mathbf{\eta} \\
(\mathbf{\%})\end{array}$ \\
\hline Blank & 1 & -452.1 & 858 & 113.7 & 131.2 & - \\
& $10^{-6}$ & 464 & 103 & 81 & 77 & 87.99 \\
\multirow{2}{*}{ DIB } & $10^{-5}$ & 447 & 70 & 76.8 & 91 & 91.84 \\
& $10^{-4}$ & 458 & 34.16 & 88.3 & 105 & 96.01 \\
& $10^{-3}$ & 463 & 16.33 & 101 & 137 & 98.09 \\
\hline
\end{tabular}

The inhibition efficiency was evaluated from the measured $\mathrm{I}_{\text {corr }}$ values using the equation:

$$
\eta_{\text {Tafel }} \%=\frac{I_{\text {corr }}^{\circ}-I_{\text {corr }}^{\mathrm{i}}}{I_{\text {corr }}^{\circ}} \times 100
$$

where, $\mathrm{I}^{\circ}$ and $\mathrm{I}^{\mathrm{i}}$ are the corrosion current density, in the absence and presence of inhibitor, respectively. As presented in Table 1, the variation in the corrosion potential values between the absence of inhibitor and the last displacement in the presence of the inhibitor is lower than $85 \mathrm{mV} / \mathrm{SCE}$. This result can confirm that the inhibitor acts as a mixed-type inhibitor [24-25]. Tafel slopes of $\beta_{c}$ and $\beta_{a}$ do not change upon the addition of DIB, which indicates that adding DIB does not change the reaction mechanism [26]. The compound is a mixed type inhibitor and its adsorption hinders the release of hydrogen gas on the metal surface, and/or reduces the metal dissolution rate into the aggressive solution by blocking the active sites on the steel surface, or even can mechanically screen the covered part of the electrode and, therefore, protects it from the action of the corrosion medium [27].

\section{AC impedance study}

The effect of each acid additive on the performance of our compound as a corrosion inhibitor for carbon steel immersed in molar acid was investigated by an EIS experiment. The obtained data by EIS measurements are graphically represented by the Nyquist plot (Fig. 2) and the impedance parameters of each 
solution, such that polarization resistance $(R p)$, double layer capacitance $\left(C_{d l}\right)$, and inhibition efficiency (IE \%)) are given in Table 2. These curves serve to understand the corrosion, by explicating the electrochemical behaviour of the carbon steel corrosion system. EIS is capable of elucidating various electrochemical processes of corrosion, such as charge-transfer and mass transfer controlled processes, interfacial layers, or resistance of the carbon steel electrolyte [28-30].

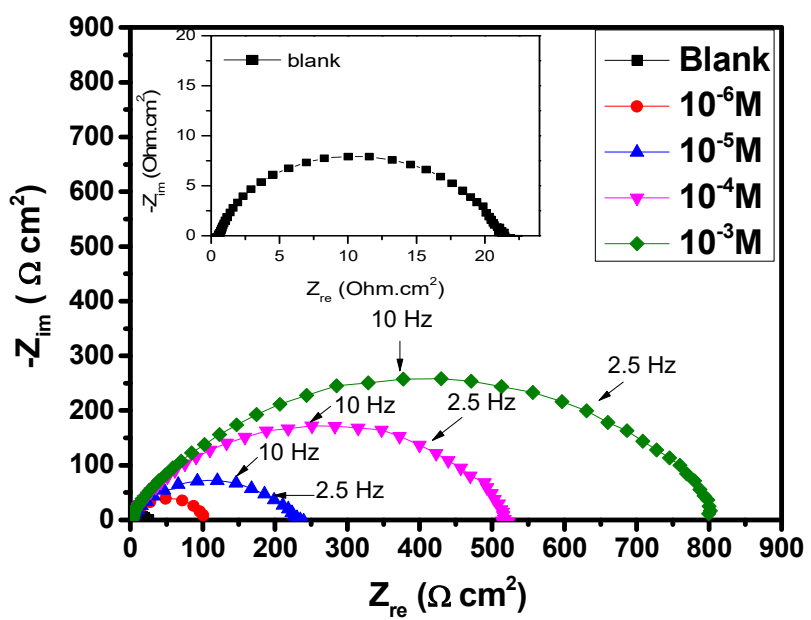

Figure 2. Nyquist plots for carbon steel at $303 \mathrm{~K}$ in $1 \mathrm{M} \mathrm{HCl}$, in various concentrations of the studied DIB inhibitor.

Table 2. EIS measurements for carbon steel immersed in $1 \mathrm{M} \mathrm{HCl}$ for $30 \mathrm{~min}$, in the absence and presence of different concentrations of the synthesized inhibitor.

\begin{tabular}{|c|c|c|c|c|c|c|c|c|}
\hline & $\begin{array}{l}\text { Conc. } \\
\text { (M) }\end{array}$ & $\begin{array}{c}R_{\mathrm{s}} \\
\left(\Omega \mathrm{cm}^{2}\right)\end{array}$ & $\begin{array}{c}\mathbf{R}_{\mathrm{ct}} \\
\left(\Omega \mathrm{cm}^{2}\right)\end{array}$ & $\begin{array}{c}10^{-4} \mathrm{Q} \\
\left(\Omega^{-1} \mathrm{~cm}^{-2} \mathrm{~s}^{-\mathrm{n}}\right)\end{array}$ & $\mathrm{n}$ & $\mathbf{X}^{2}$ & $\begin{array}{c}C_{d l} \\
\left(\mu F \mathrm{~cm}^{-2}\right)\end{array}$ & $\begin{array}{c}\eta \\
(\%)\end{array}$ \\
\hline Blank & $\overline{1 \mathrm{M}}$ & $0.57 \pm 0.18$ & $20.14 \pm 0.49$ & $2.40 \pm 0.14$ & $0.86 \pm 0.57$ & 0.114 & 112.04 & - \\
\hline \multirow{4}{*}{ IB } & $10^{-6}$ & $0,66 \pm 0.12$ & $103 \pm 0.21$ & $1.62 \pm 0.05$ & $0.83 \pm 0.53$ & 0.006 & 70.05 & 80.45 \\
\hline & $10^{-5}$ & $0.85 \pm 0.29$ & $223 \pm 8.65$ & $1.12 \pm 0.03$ & $0.77 \pm 0.51$ & 0.036 & 38.70 & 90.97 \\
\hline & $10^{-4}$ & $1.15 \pm 0.31$ & $503 \pm 8.64$ & $0.68 \pm 0.02$ & $0.79 \pm 0.50$ & 0.021 & 28.08 & 95.99 \\
\hline & $10^{-3}$ & $0.94 \pm 0.50$ & $780 \pm 19.35$ & $0.52 \pm 0.02$ & $0.77 \pm 0.51$ & 0.024 & 19.96 & 97.42 \\
\hline
\end{tabular}

It appears from Fig. 2 that the plots were composed of one capacitive loop of which diameter was significantly changed after the inhibitor addition, and the larger diameter was observed at $10^{-3} \mathrm{M}$ of DIB. Furthermore, these impedance diagrams are not perfect semicircles; this difference has been attributed to frequency dispersion and inhomogeneities of the surface [31-33]. The equivalent circuit model employed for these systems is presented in Fig. 3.

In the equivalent circuit, $R_{s}$ is the solution resistance, $R_{c t}$ is the charge transfer resistance and CPE is a constant phase element. An excellent fit with this model was obtained from all experimental data. 

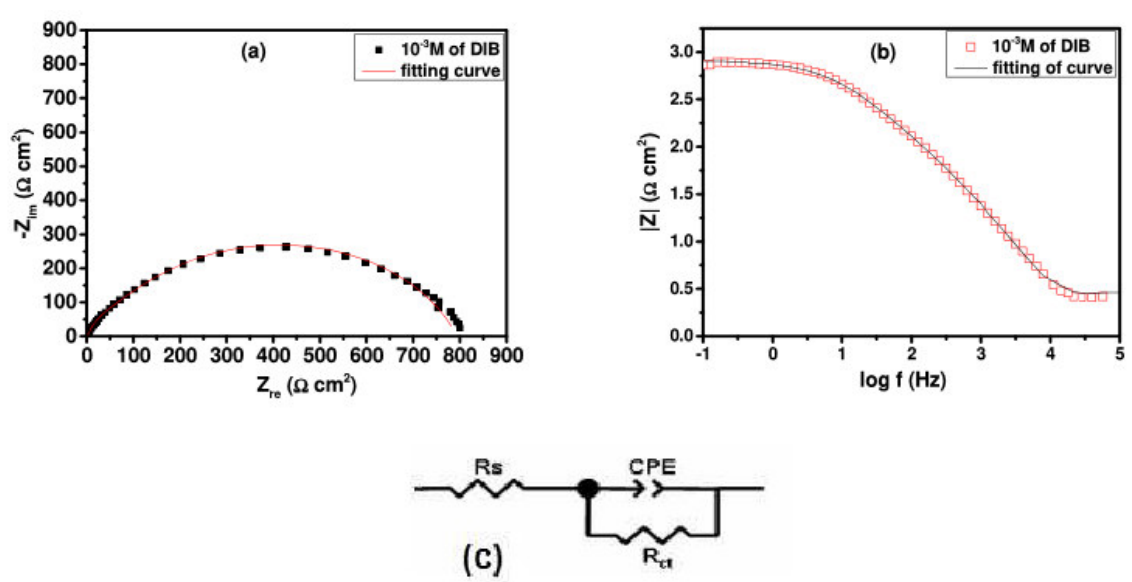

Figure 3. EIS Nyquist (a) and Bode (b) diagrams for C-steel in a $1.0 \mathrm{M} \mathrm{HCl}$ solution with $10^{-3} \mathrm{M}$ of DIB and (c) equivalent circuit used to fit the impedance spectra.

The impedance of the constant phase element (CPE) is given by [34-35]:

$$
Z_{\mathrm{CPE}}=\frac{1}{\left[Y_{0}(i w)^{\mathrm{n}}\right]}
$$

where $\mathrm{Y}_{0}$ is the magnitude of the CPE, $w$ is the angular frequency and $n$ is a physical parameter which gives the interphase properties of the working electrode. The double layer capacitance can be calculated by using the following equation [35-36]:

$$
C_{\mathrm{dl}}=\left(Q \times R^{1-\mathrm{n}}\right)^{\frac{1}{\mathrm{n}}}
$$

where $\mathrm{Q}$ is the CPE constant (in $\left.\Omega^{-1} \mathrm{~cm}^{-2} \mathrm{~s}^{-\mathrm{n}}\right)$, $\mathrm{n}$ is the CPE-power $(0<\mathrm{n}<1)$ and $\mathrm{R}_{\mathrm{ct}}$ is the charge-transfer resistance $\left(\Omega \mathrm{cm}^{2}\right)$.

From the data of Table 2, it is found that DIB concentrations increase is proportional to $R_{c t}$ values, but the $C_{d l}$ values tend to decrease. This decrease in the $\mathrm{C}_{\mathrm{dl}}$ values is due to the adsorption of the inhibitor molecules replacing water at the metal-solution interface, and can be caused by a decrease in the local dielectric constant and/or by the increase in the thickness of the double layer [3739]. These results show that the inhibitor molecules act by adsorption at the metal-solution interface.

The inhibition efficiency can be calculated by $\mathrm{R}_{\mathrm{ct}}$, using the following formula:

$$
\eta_{\mathrm{Z}}=\frac{R_{\mathrm{ct}}^{\mathrm{i}}-R_{\mathrm{ct}}^{\circ}}{R_{\mathrm{ct}}^{\mathrm{i}}} \times 100
$$

where $\mathrm{R}_{\text {ct }}^{\circ}$ and $\mathrm{R}_{\text {ct }}^{\mathrm{i}}$ are the charge transfer resistance, in the absence and presence of the inhibitor, respectively.

\section{Adsorption isotherm}

Generally, the adsorption of an inhibitor occurs by two means: physisorption and/or chemisorption. The first one involves a weak undirected interaction, due to electrostatic attraction between inhibiting organic ions or dipoles and the electrically charged surface of the metal. The latter one occurs by sharing or charge transfer from the adsorbate to the atoms of the metal surface, in order to 
form a coordinated bond, and it is called chemical adsorption or chemisorption. In general, an adsorption isotherm is an invaluable curve describing the phenomenon governing the retention or release of substances from the aqueous porous media to a solid phase at a constant temperature [40]. The adsorption equilibrium (the ratio between the adsorbed amount with that remaining in the solution) is established when an adsorbate containing phase is in contact with the adsorbent for sufficient time. From this point of view, the current model has excellence in that it has only a fitting parameter that quantifies the concentration dependence of adsorption. In our study, several adsorption isotherms (Langmuir, Temkin, Frumkin, etc.) were attempted, and the Langmuir adsorption isotherm was found to fit well with the experimental data obtained for DIB. The Langmuir isotherm is given by the following equation [41]:

$$
\frac{\theta}{1-\theta}=K_{\mathrm{ads}} C_{\mathrm{inh}}
$$

where $K_{a d s}$ is related to the standard Gibbs free energy of adsorption, $C$ is the inhibitor concentration and $\theta$ is the degree of surface coverage of DIB at the metallic surface. The values of surface coverage obtained at different concentrations of DIB from PDP experiments were used to obtain the Langmuir adsorption isotherm plots (Fig. 4) that enabled the calculation of $\mathrm{K}_{\mathrm{ads}}$ values.

$\mathrm{K}_{\mathrm{ads}}$ is related to the standard free energy of adsorption $\left(\Delta \mathrm{G}^{0}{ }_{\mathrm{ads}}\right)$ by the following equation [39]:

$$
\Delta G_{\mathrm{ads}}^{\circ}=-R T \ln \left(55.5 K_{\mathrm{ads}}\right)
$$

where $\mathrm{R}$ is the universal gas constant, $\mathrm{T}$ is the absolute temperature and the value of 55.5 is the molar concentration of water in the solution. From Fig 4, it can be seen a very good fit with the regression coefficient up to 0.99 , and the obtained line had a slope very close to unity, which suggests that the experimental data are well described by Langmuir isotherm, and exhibit single-layer adsorption characteristics. This kind of isotherm involves the assumption of no interaction between the adsorbed species on the electrode surface. The calculated values of $\mathrm{K}_{\mathrm{ads}}$ and $\Delta \mathrm{G}^{0}$ ads are indicated in Table 3. High values of $\mathrm{K}_{\mathrm{ads}}$ suggest that the adsorption of DIB onto the carbon steel surface is easy and strong $[33,42]$.

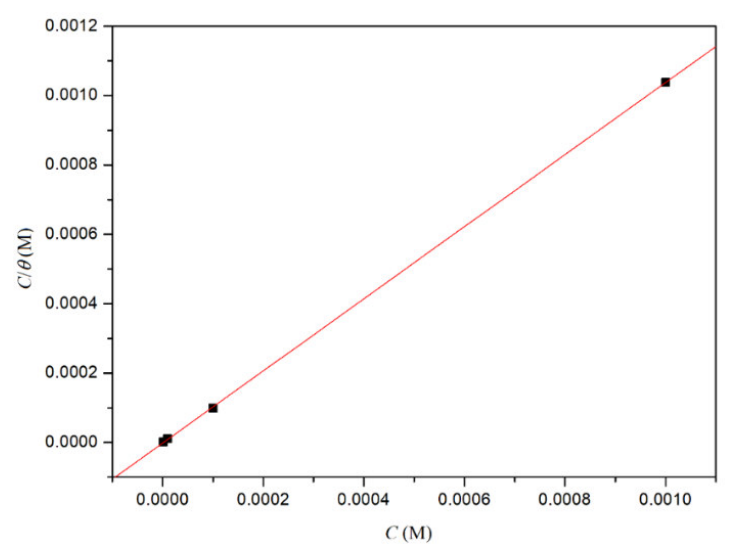

Figure 4. Langmuir adsorption isotherm plot for carbon steel in a $1 \mathrm{M} \mathrm{HCl}$ solution, at different concentrations of the studied inhibitors. 

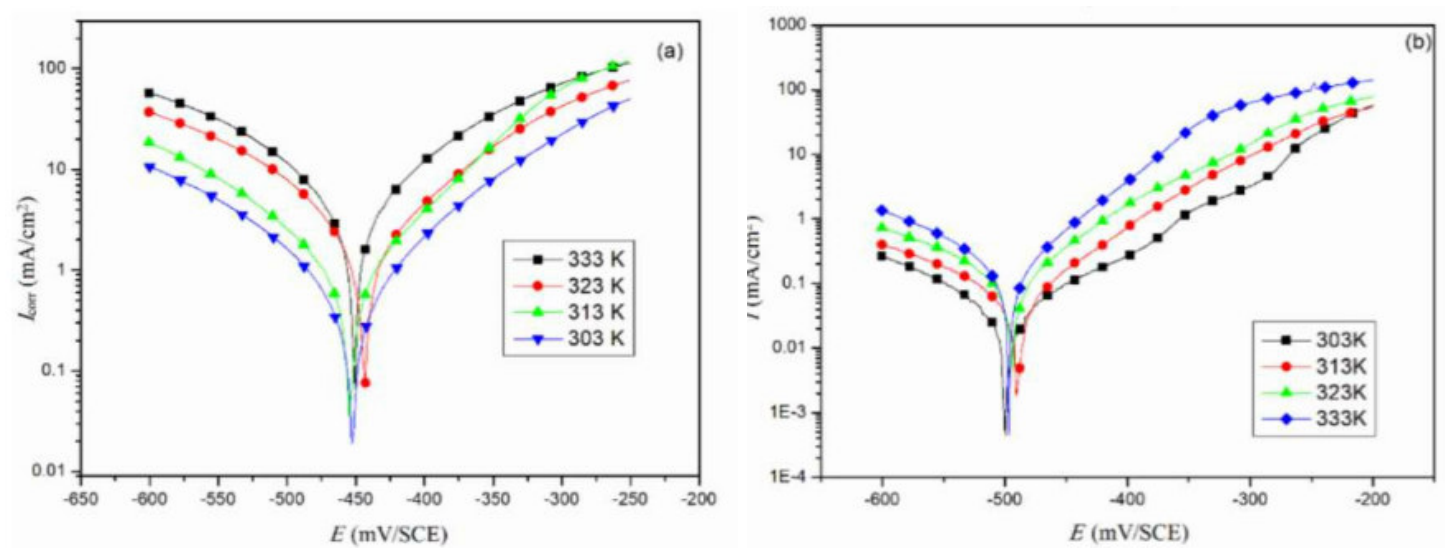

Figure 5. Effect of temperature on the behavior of carbon steel/1 $\mathrm{M} \mathrm{HCl}$ interface in (a) an uninhibited solution, and (b) at $10^{-3} \mathrm{M}$ of DIB.

Table 3. Values of $\mathrm{K}_{\mathrm{ads}}$ and $\Delta \mathrm{G}_{\text {ads }}^{\circ}$ for carbon steel with DIB in $1 \mathrm{M} \mathrm{HCl}$, at $303 \mathrm{~K}$.

\begin{tabular}{ccccc}
\hline Inhibitor & Slope & $\begin{array}{c}\mathbf{K}_{\text {ads }} \\
\left(\mathbf{M}^{-\mathbf{1}}\right)\end{array}$ & $\begin{array}{c}-\mathbf{\Delta} \mathbf{G}_{\text {ads }}^{\circ} \\
\left(\mathbf{K J}_{\mathbf{m o l}} \mathbf{m o l}^{\mathbf{1}}\right)\end{array}$ & $\mathbf{R}^{\mathbf{2}}$ \\
\hline DIP & 1.03 & 795950 & 44.35 & 0.99998 \\
\hline
\end{tabular}

\section{Effect of temperature}

To ensure the effectiveness of DIB under various conditions, tests were performed in a $1.0 \mathrm{M} \mathrm{HCl}$ solution, at different temperatures in the range from 303 to $333 \mathrm{~K}$ (Fig. 5).

Table 4. Temperature influence on the PDP parameters for carbon steel in $1 \mathrm{M} \mathrm{HCl}$, with and without $\mathrm{HCl}(1 \mathrm{M})+10^{-3} \mathrm{M}$ of DIB at the temperature range from $303 \mathrm{~K}$ to 333 $\mathrm{K}$.

\begin{tabular}{cccccc}
\hline Inhibitor & $\begin{array}{c}\mathbf{T} \\
\mathbf{( K )}\end{array}$ & $\begin{array}{c}\mathbf{E}_{\text {corr }} \\
(\mathbf{m V} / \mathbf{S C E})\end{array}$ & $\begin{array}{c}\mathbf{I}_{\text {corr }} \\
\left(\mathbf{m A ~ c m} \mathbf{~ c m}^{-2}\right.\end{array}$ & $\mathbf{n ( \% )}$ & $\boldsymbol{\theta}$ \\
\hline \multirow{6}{*}{ Blank } & 303 & -452 & 507 & - & - \\
& 313 & -454 & 860 & - & - \\
& 323 & -443 & 1840 & - & - \\
& 333 & -450 & 2800 & - & - \\
& & & & & \\
\multirow{6}{*}{ DIB } & 303 & -463 & 16.33 & 98.09 & 0.98 \\
& 313 & -457 & 35 & 95.93 & 0.95 \\
& 323 & -459 & 114 & 93.80 & 0.93 \\
\hline
\end{tabular}

Values of $\mathrm{I}_{\text {corr }}$ obtained in the presence and absence of DIB are increased with higher temperatures, and are much higher in the aggressive solution, which means the corrosion inhibition process by DIB. The activation energy $\left(E_{a}\right)$ was calculated using Arrhenius equation [24]:

$$
I_{\text {corr }}=A \exp \left(-\frac{E_{\mathrm{a}}}{R T}\right)
$$

where $E_{a}$ is the apparent activation corrosion energy, $R$ is the universal gas constant and $\mathrm{A}$ is the Arrhenius pre-exponential constant. 
The Arrhenius plots of the logarithm of the current density versus $1 / \mathrm{T}$ for carbon steel in $1 \mathrm{M} \mathrm{HCl}$, in the presence and absence of $10^{-3} \mathrm{M}$ of DIB are shown in Fig. 6.

Straight lines are obtained with a slope of $\left(E_{a} / R\right)$. The corresponding activation parameters obtained from this graph are given in Table 5. The value of $E_{a}$ found for DIB is lower than that obtained for the aggressive solution. The decrease in the apparent activation energy may be interpreted as the chemical adsorption of the inhibitor onto the steel surface $[29,43]$.

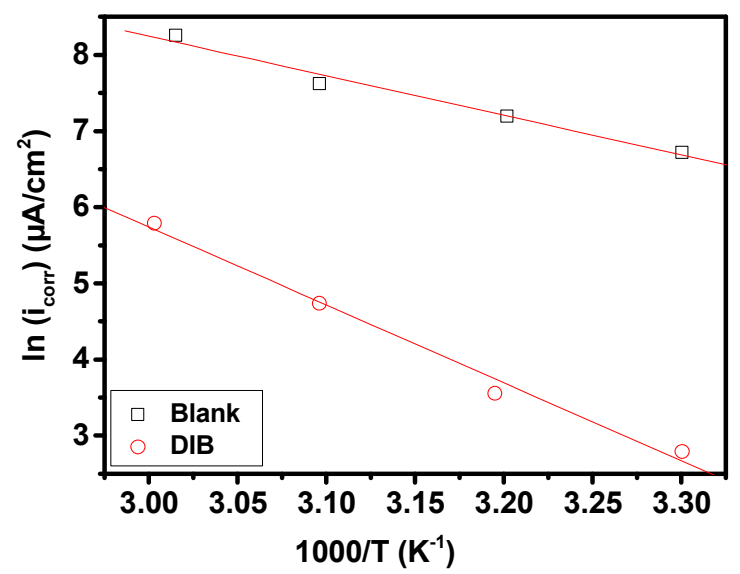

Figure 6. Arrhenius plots for carbon steel in $1 \mathrm{M} \mathrm{HCl}$, in the absence and presence of $10^{-3} \mathrm{M}$ of DIB.

Table 5. Corrosion kinetic parameters for carbon steel in $1 \mathrm{M} \mathrm{HCl}$, in the absence and presence of $10^{-3} \mathrm{M}$ of DIB.

\begin{tabular}{cccc}
\hline Inhibitor & $\begin{array}{c}\mathbf{E}_{\mathbf{a}} \\
\left(\mathbf{k J ~ m o l}^{-\mathbf{1}}\right)\end{array}$ & $\begin{array}{c}\Delta \mathbf{H}_{\mathbf{a}} \\
\left(\mathbf{k J ~ m o l}^{-\mathbf{1}}\right)\end{array}$ & $\begin{array}{c}\Delta \mathbf{S}_{\mathbf{a}} \\
\left(\mathbf{J ~ m o l}^{-1} \mathbf{K}^{-\mathbf{1}}\right)\end{array}$ \\
\hline Blank & 43.189 & 33.25 & -80.51 \\
DIB & 85.12 & 82.48 & 49.33 \\
\hline
\end{tabular}

The transition state equation was used to calculate the enthalpy $\left(\Delta \mathrm{H}_{\mathrm{a}}\right)$ and entropy of activation $\left(\Delta \mathrm{S}_{\mathrm{a}}\right)$ for the metal dissolution and inhibition process. The transition state equation is [44]:

$$
I_{\text {corr }}=\frac{R T}{N h} \exp \left(\frac{\Delta S_{\mathrm{a}}}{R}\right) \exp \left(-\frac{\Delta H_{\mathrm{a}}}{R T}\right)
$$

where $\mathrm{R}$ is the universal gas constant, $\mathrm{h}$ is Planck's constant, $\mathrm{N}$ is Avogadro's number, $\Delta \mathrm{S}_{\mathrm{a}}$ is the entropy of activation and $\Delta \mathrm{H}_{\mathrm{a}}$ is the enthalpy of activation.

Fig. 7 shows a graph of $\ln \left(\mathrm{I}_{\text {corr }} / \mathrm{T}\right)$ against $1000 / \mathrm{T}$. Straight lines are obtained with a slope $\left(-\Delta \mathrm{H}_{\mathrm{a}} / \mathrm{R}\right)$ and an interception $\left(\mathrm{LnR} / \mathrm{Nh}+\Delta \mathrm{S}_{\mathrm{a}} / \mathrm{R}\right)$, from which the values of $\Delta \mathrm{H}_{\mathrm{a}}$ and $\Delta \mathrm{S}_{\mathrm{a}}$ are calculated and are summarized in Table 5.

Inspection of these data suggests that $\Delta \mathrm{H}_{\mathrm{a}}$ values for the dissolution reaction of carbon steel in a $1 \mathrm{M} \mathrm{HCl}$ solution in the presence of DIB are higher $(82.48 \mathrm{~kJ}$ $\left.\mathrm{mol}^{-1}\right)$ than in the absence of the inhibitors $\left(33.25 \mathrm{~kJ} \mathrm{~mol}^{-1}\right)$. Positive signs values of $\Delta \mathrm{H}_{\mathrm{a}}$ reflect the endothermic nature of carbon steel dissolution process, suggesting that the dissolution of carbon steel is slow $[27,30]$. 
For the entropy of activation $\left(\Delta \mathrm{S}_{\mathrm{a}}\right)$, Table 5 shows that $\Delta \mathrm{S}_{\mathrm{a}}$ value is increased in the presence of DIB. This observation reveals that an increase in disordering takes place on going from reactants to the activated complex $[37,41]$.

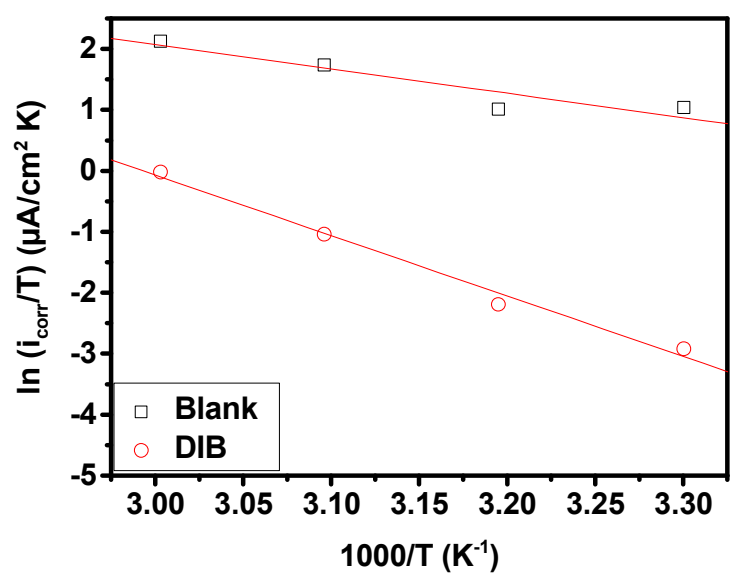

Figure 7. Transition-state plots for carbon steel in a $1 \mathrm{M} \mathrm{HCl}$ solution, in the absence and presence of $10^{-3} \mathrm{M}$ of DIB.

\section{DFT results}

To rationalize the observed corrosion inhibition of the synthesized compound DIB, a certain number of its electronic properties in neutral and protonated forms is calculated at the B3LYP level of theory (Table 6). The optimized structure of the tilted compound, in its neutral and protonated forms, is shown in Fig. 8.

Table 6. Electronic properties $(\mathrm{eV})$ of neutral and protonated forms of DIB calculated at the B3LYP/6-311+G (d, p) level of theory.

\begin{tabular}{ccc}
\hline \multirow{2}{*}{ Electronic parameters } & \multicolumn{2}{c}{ DIB } \\
\cline { 2 - 3 } & Neutral & Protonated \\
\hline IP & 6.44 & 7.41 \\
GA & 0.94 & 1.94 \\
$\chi$ & 5.50 & 5.47 \\
$\eta$ & 3.69 & 4.68 \\
$\mathrm{~S}$ & 2.75 & 2.74 \\
$\omega$ & 0.18 & 0.18 \\
$\chi \mathrm{Fe}$ & 2.48 & 4.00 \\
$\eta_{\mathrm{Fe}}$ & 7.00 & 7.00 \\
$\Delta \mathrm{N}$ & 0.00 & 0.00 \\
$\mathrm{DM}$ & 0.60 & 0.42 \\
& 8.51 & 16.81 \\
\hline
\end{tabular}

As it can be remarked from Fig. 9, in the neutral form, HOMO and LUMO orbital of the synthesized inhibitor are mainly delocalized over benzimidazole moiety, while there is no delocalization in the decyl and methylisoxazol-2ylmethyl substituted group. Hence, one can conclude that the efficiency inhibition of the tilted compound is due to the benzimidazole moiety. Thus, the current synthesized inhibitor may have donor/acceptor electrons of atom sites in triazol and triazepin-8-one moieties to/from the d-orbitals of iron. In the protonation form, there is a major change in the delocalization of the HOMO distribution. In one hand, the HOMO region is located on 1-decyl-2-[(5- 
methylisoxazol-2-yl)methyl] moiety (Fig. 9). On the other hand, the LUMO region is slightly changed compared to the neutral form (Fig. 9).
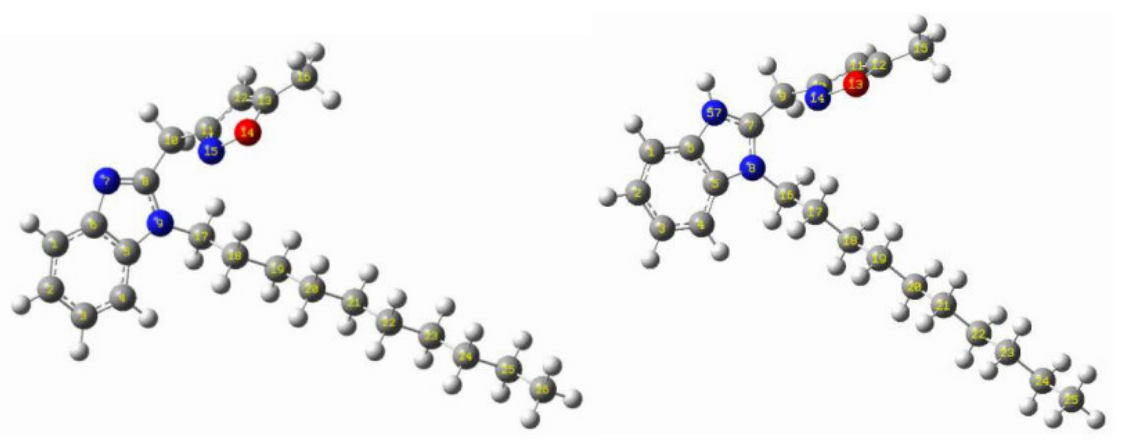

Figure 8. Optimized structure of the tilted compound (left) and its protonated form (right) obtained at the B3LYP/6-31+G(d, p) level of theory of 1-decyl-2-[(5methylisoxazol-2-yl)methyl]benzimidazole.

The frontier HOMO and LUMO orbitals of the synthesized inhibitor and its protonated form are shown in Fig. 9.

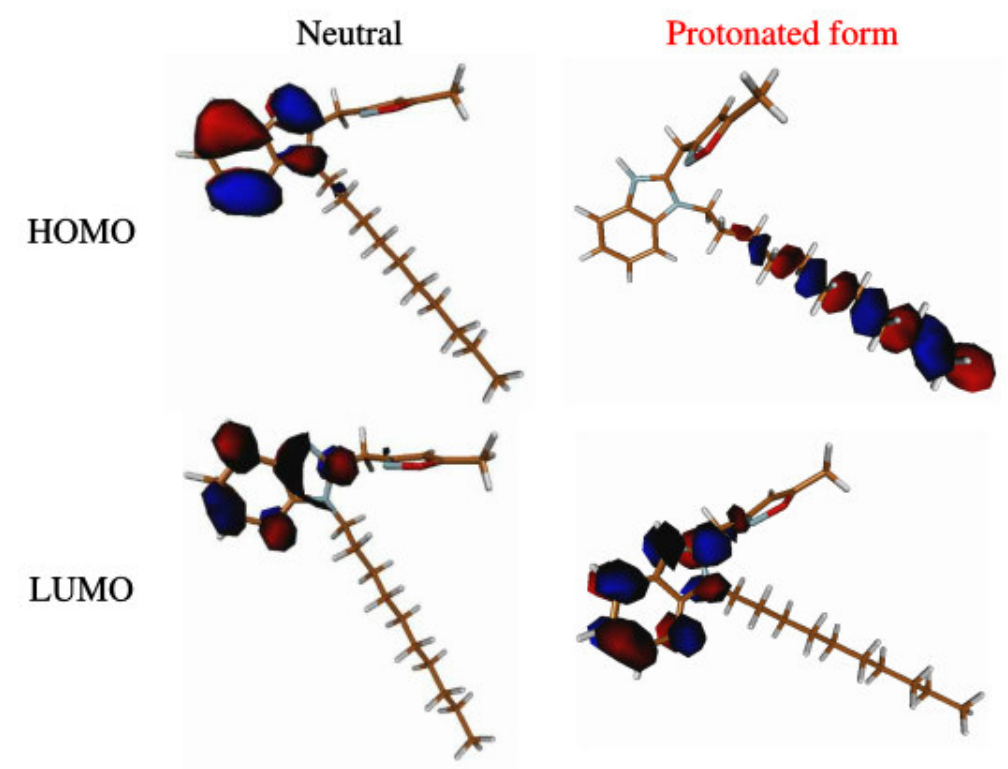

Figure 9. HOMO and LUMO frontier molecular orbitals of the synthesized inhibitor and its protonated form (Isovalue of 0.04 ).

Therefore, to determine the active site in benzimidazole moiety, Mulliken atomic charges were calculated at the B3LYP level of theory. The results in Table 7 reveal that some of the atomic centres charged negatively, while others charged positively. For instance, the benzene ring in benzimidazole plays the role of the nucleophile or electron donator (with atomic negative charges), while the nitrogen atom of imidazole cycle plays the role of an electron acceptor, with a positive charge of $0.45 \mathrm{C}$. The number of transferred electrons from the inhibitor to the metal surface $(\Delta N)$ is of 0.6 , and 0.42 for the protonated form. This suggests that the neutral and protonated forms have a tendency to donate electrons to the metal surface. It is reported that the inhibition efficiency increased with electron-donating ability to the metal surface $(\Delta N)[45,46]$. As 
expected, it is worth to mention that upon protonation, there is a large increase in the dipole moment of the inhibitor (Table 6).

Table 7. Calculated Mulliken atomic charges of the tilted compound.

\begin{tabular}{cc}
\hline Atomic center & Mulliken atomic charges \\
\hline C1 & -0.44543 \\
C2 & -0.34761 \\
C3 & -0.31363 \\
C4 & -0.13507 \\
C5 & 0.41576 \\
C6 & 0.11282 \\
N7 & -0.04454 \\
C8 & -0.43164 \\
N9 & 0.44907 \\
\hline
\end{tabular}

\section{Conclusion}

In the present report, the synthesized DIB inhibitor shows good inhibition properties for the corrosion of carbon steel in $1 \mathrm{M} \mathrm{HCl}$. The inhibition efficiency, $\eta$, increases with increasing concentrations of the inhibitor, reaching its maximum value at $10^{-3} \mathrm{M}$ of concentration. The corrosion process is inhibited by the adsorption of DIB onto the steel surface, and the adsorption of this inhibitor fits a Langmuir isotherm model at $303 \mathrm{~K}$. The calculated values of $\Delta \mathrm{G}_{\mathrm{ads}}{ }^{\mathrm{o}}$ reveal that the adsorption mechanism of DIB onto the carbon steel surface in a $1 \mathrm{M} \mathrm{HCl}$ solution is mainly physisorption and chemisorption. Based on the Tafel polarization results, DIB can be classified as a mixed type inhibitor. The efficiency of this inhibitor is found to decrease proportionally with increasing temperatures (303-333 K). The double layer capacitance obtained from EIS measurements decreases with the augmentation of the inhibitor concentration, confirming an adsorption process of DIB onto the carbon steel surface. DFT calculations show that the corrosion inhibition efficiency of the tilted and its adsorption on the metal surface is mainly referred to the presence of benzimidazole moiety.

\section{References}

1. Schmitt G. Application of inhibitors for acid media: report prepared for the European federation of corrosion working party on inhibitors. British Corros J. 1984;19(4):165-76.

2. Bentiss F, Lagrenee M, Traisnel M, et al. The corrosion inhibition of mild steel in acidic media by a new triazole derivative. Corros Sci. 1999;41(4):789-803.

3. Bentiss F, Lagrenee M, Traisnel M. 2, 5-bis (n-pyridyl)-1, 3, 4-oxadiazoles as corrosion inhibitors for mild steel in acidic media. Corrosion. 2000;56(7):733-42.

4. Bentiss F, Traisnel M, Lagrenee $M$. Influence of 2, 5-bis (4dimethylaminophenyl)-1, 3, 4-thiadiazole on corrosion inhibition of mild steel in acidic media. J Appl Electrochem. 2001;31(1):41-8. 
5. Cruz J, Martínez-Aguilera LM, Salcedo R, et al. Reactivity properties of derivatives of 2-imidazoline: an ab initio DFT study. Int J Quantum Chem. 2001;85(4-5):546-56.

6. Cruz J, Pandiyan T, Garcia-Ochoa E. A new inhibitor for mild carbon steel: electrochemical and DFT studies. J Electroanal Chem. 2005;583(1):8-16.

7. Barker HA, Smyth RD, Weissbach $\mathrm{H}$, et al. Isolation and properties of crystalline cobamide coenzymes containing benzimidazole or 5, 6dimethylbenzimidazole. J Biol Chem. 1960;235(2):480-8.

8. Wagner EC, Millett WH. Benzimidazole. Org Synth. 1943:12.

9. El-Masry AH, Fahmy HH, Ali Abdelwahed SH. Synthesis and antimicrobial activity of some new benzimidazole derivatives. Molecules. 2000;5(12):1429-38.

10. Tebbe MJ, Spitzer WA, Victor F, et al. Antirhino/enteroviral vinylacetylene benzimidazoles: a study of their activity and oral plasma levels in mice. J Med Chem. 1997;40(24):3937-46.

11. Subudhi B, Panda P, Kundu T, et al. Synthesis and biological evaluation of some benzimidazole and thiazolidinone derivatives. $J$ Pharm Res. 2007;6:114-8.

12. Aydin S, Beis R, Can ÖD. Analgesic and antispasmodic activities of 2-(2nitro-phenyl)-1H-benzimidazole 5-carboxylic acid: evidence for the importance of the 2-(o-substituted phenyl) group. Die Pharmazie-An Int J Pharm Sci. 2003;58(6):405-8.

13. Bhatt AK, Karadiya H, Shah PR, et al. Synthesis of benzimidazole derivatives and their antibacterial and antifungal activities. Indian $\mathrm{J}$ Heter Chem. 2003;13(2):187-8.

14. Sebhaoui J, Boudalia M, El Bakri Y, et al. Corrosion Control of Mild Steel in Hydrochloric Acid by a 1, 5-Benzodiazepine Derivative: Electrochemical and Adsorption studies. J Mater Environ Sci. 2017;8:3666-3675.

15. El Bakri Y, Boudalia M, Echihi S, et al. Performance and theoretical study on corrosion inhibition of new triazolopyrimidine derivative for carbon steel in hydrochloric acid. J Mater Environ Sci. 2017;8(2):378-88.

16. El Bakri Y, Ramli Y, Essassi EM, et al. Synthesis, crystal structure, spectroscopic characterization, Hirshfeld surface analysis, and DFT calculations of 1, 4-dimethyl-2-oxo-pyrimido 1, 2-a. benzimidazole hydrate. J Mol Struct. 2018;1152:154-62.

17. Sebhaoui J, El Bakri Y, Essassi EM, et al. (4Z)-4-(2-Oxopropylidene)-2, 3,4,5-tetrahydro-1H-1, 5-benzodiazepin-2-one. IUCrData. 2017;2(7):x171057.

18. Sebhaoui J, El Bakri Y, Rayni I, et al. (4Z)-4-(2-Oxopropylidene)-1, 3-bis (prop-2-en-1-yl)-2, 3, 4, 5-tetrahydro-1H-1， 5-benzodiazepin-2-one. IUCrData. 2017;2(4):x170493.

19. El Bakri Y, Harmaoui A, Essassi EM, et al. 9-Ethyl-6-methyl-7H-1, 2, 4triazolo 4, 3-b]1, 2, 4] triazepin-8 (9H)-one. IUCrData. 2016;1(12):x161897.

20. Sebhaoui J, El Bakri Y, Rayni I, et al. 4-(2-Oxopropyl)-1, 3-bis (prop-2-yn1-yl)-2, 3, 4, 5-tetrahydro-1, 5-benzodiazepin-2 (1H)-one. IUCrData. 2016;1(6):x161013. 
21. Frisch MJ, Trucks GW, Schlegel HB, et al. Gaussian 09, revision a. 02, gaussian. Inc., Wallingford, CT. 2009;200.

22. Pearson RG. Absolute electronegativity and hardness: application to inorganic chemistry. Inorg Chem. 1988;27(4):734-40.

23. Tomasi J, Mennucci B, Cammi R. Quantum mechanical continuum solvation models. Chem Rev. 2005;105(8):2999-3094.

24. Verma C, Quraishi MA, Singh A. 2-Amino-5-nitro-4, 6-diarylcyclohex-1ene-1, 3, 3-tricarbonitriles as new and effective corrosion inhibitors for mild steel in $1 \mathrm{M} \mathrm{HCl}$ : Experimental and theoretical studies. J Mol Liq. 2015;212:804-12.

25. El Aoufir Y, Lgaz H, Bourazmi H, et al. Quinoxaline derivatives as corrosion inhibitors of carbon steel in hydrochloridric acid media: electrochemical, DFT and Monte Carlo simulations studies. J Mater Environ Sci. 2016;7(12):4330-47.

26. Verma C, Ebenso EE, Bahadur I, et al. 5-(Phenylthio)-3H-pyrrole-4carbonitriles as effective corrosion inhibitors for mild steel in $1 \mathrm{M} \mathrm{HCl}$ : Experimental and theoretical investigation. J Mol Liq. 2015;212:209-18.

27. Salarvand Z, Amirnasr M, Talebian M, et al. Enhanced corrosion resistance of mild steel in $1 \mathrm{M} \mathrm{HCl}$ solution by trace amount of 2-phenyl-benzothiazole derivatives: Experimental, quantum chemical calculations and molecular dynamics (MD) simulation studies. Corros Sci. 2017;114:133-145.

28. Sasikumar Y, Adekunle AS, Olasunkanmi LO, et al. Experimental, quantum chemical and Monte Carlo simulation studies on the corrosion inhibition of some alkyl imidazolium ionic liquids containing tetrafluoroborate anion on mild steel in acidic medium. J Mol Liq. 2015;211:105-18.

29. Anupama KK, Ramya K, Joseph A. Electrochemical and computational aspects of surface interaction and corrosion inhibition of mild steel in hydrochloric acid by Phyllanthus amarus leaf extract (PAE). J Mol Liq. 2016;216:146-55.

30. Yadav M, Gope L, Kumari N, et al. Corrosion inhibition performance of pyranopyrazole derivatives for mild steel in $\mathrm{HCl}$ solution: Gravimetric, electrochemical and DFT studies. J Mol Liq. 2016;216:78-86.

31. Yadav M, Kumar S, Sinha RR, et al. New pyrimidine derivatives as efficient organic inhibitors on mild steel corrosion in acidic medium: electrochemical, SEM, EDX, AFM and DFT studies. J Mol Liq. 2015;211:135-45.

32. Singh P, Srivastava V, Quraishi MA. Novel quinoline derivatives as green corrosion inhibitors for mild steel in acidic medium: Electrochemical, SEM, AFM, and XPS studies. J Mol Liq. 2016;216:164-73.

33. Gupta NK, Verma C, Quraishi MA, et al. Schiff's bases derived from 1-lysine and aromatic aldehydes as green corrosion inhibitors for mild steel: experimental and theoretical studies. J Mol Liq. 2016;215:47-57.

34. Kumar R, Chahal S, Kumar S, et al. Corrosion inhibition performance of chromone-3-acrylic acid derivatives for low alloy steel with theoretical modeling and experimental aspects. J Mol Liq. 2017;243:439-50.

35. Lgaz H, Salghi R, Jodeh S, et al. Effect of clozapine on inhibition of mild steel corrosion in 1.0 M HCl medium. J Mol Liq. 2017;225:271-80. 
36. Messali M, Lgaz H, Dassanayake R, et al. Guar gum as efficient non-toxic inhibitor of carbon steel corrosion in phosphoric acid medium: Electrochemical, surface, DFT and MD simulations studies. J Mol Struct. 2017;1145:43-54.

37. El Aoufir Y, Sebhaoui J, Lgaz H, et al. Corrosion inhibition of carbon steel in $1 \mathrm{M} \mathrm{HCl}$ by 1, 5-benzodiazepine derivative: Experimental and molecular modeling studies. J Mater Environ Sci. 2017;8(6):2161-73.

38. Laabaissi $\mathrm{T}$, Lgaz $\mathrm{H}$, Oudda $\mathrm{H}$, et al. Comparative study of corrosion inhibition effect of benzodiazepine derivative on the carbon steel surface in 2.0 $\mathrm{M} \mathrm{H}_{3} \mathrm{PO}_{4}$ and $1.0 \mathrm{M} \mathrm{HCl}$ mediums: Electrochemical, theoretical and Monte Carlo simulations studies. J Mater Environ Sci. 2017;8(3):1054-67.

39. Salghi R, Jodeh S, Ebenso EE, et al. Inhibition of C-steel corrosion by green tea extract in hydrochloric solution. Int J Electrochem Sci. 2017;12:3283-95.

40. Ali I, Salghi R, Jodeh S, et al. 6-phenylpyridazin-3 (2H) one as New Corrosion Inhibitor for $\mathrm{C} 38$ Steel in $1 \mathrm{M} \mathrm{HCl}$. Int $\mathrm{J}$ Electroch Sci. 2017;12:3309-22.

41. El Aoufir Y, El Bakri Y, Lgaz H, et al. Understanding the adsorption of benzimidazole derivative as corrosion inhibitor for carbon steel in $1 \mathrm{M} \mathrm{HCl}$ : experimental and theoretical studies. J Mater Environ Sci. 2017;8:3290-302.

42. Yadav M, Sinha RR, Kumar S, et al. Synthesis and application of new acetohydrazide derivatives as a corrosion inhibition of mild steel in acidic medium: Insight from electrochemical and theoretical studies. J Mol Liq. 2015;208:322-32.

43. Murulana LC, Kabanda MM, Ebenso EE. Investigation of the adsorption characteristics of some selected sulphonamide derivatives as corrosion inhibitors at mild steel/hydrochloric acid interface: Experimental, quantum chemical and QSAR studies. J Mol Liq. 2016;215:763-79.

44. Singh DK, Kumar S, Udayabhanu G, et al. 4 (N, N-dimethylamino) benzaldehyde nicotinic hydrazone as corrosion inhibitor for mild steel in $1 \mathrm{M}$ $\mathrm{HCl}$ solution: An experimental and theoretical study. J Mol Liq. 2016;216:738-46.

45. Torres VV, Rayol VA, Magalhães M, et al. Study of thioureas derivatives synthesized from a green route as corrosion inhibitors for mild steel in $\mathrm{HCl}$ solution. Corros Sci. 2014;79:108-18.

46. Ju H, Kai ZP, Li Y. Aminic nitrogen-bearing polydentate Schiff base compounds as corrosion inhibitors for iron in acidic media: a quantum chemical calculation. Corros Sci. 2008;50(3):865-71. 